\title{
In-vitro Dissolution Study of Lamotrigine Tablet in the Presence of Different Medium
}

\author{
Samina Alam, Ayesha Qadir, Tanveer Alam, Aqsa Abdul Aziz, Faiza Jabbar, Hareema \\ Hashmi, Khushbu Sabahat, Minal Zahid, Mishra Binte Naeem
}

Faculty of Pharmacy, Jinnah University for Women, Karachi, Pakistan

Received: 29-07-2021 / Revised Accepted: 25-08-2021 / Published: 01-09-2021

\begin{abstract}
The reason for accomplished is to get a superior information in regards to the brief dissolution of lamotrigine tablet in an individual dissolution medium to accomplish the most quick, rapid and significant restorative impact of the lamotrigine tablet. In this single portion study, it was tracked down that the test and reference results of lamotrigine tablets conformed to the administrative rules for identicalness regarding rate and degree of assimilation as indicated by the directions of FDA. By perception we reasoned that lamotrigine shows interaction with tea extract that its absorbance diminishes with time it ought not to take with tea.
\end{abstract}

Keywords: Lamotrigine, tablets, Dissolution

\section{INTRODUCTION}

Lamotrigine is an antiepileptic specialist which blocks voltage-subordinate sodium channels, subsequently forestalling excitatory synapse discharge. Clinical proof demonstrates that lamotrigine is successful against incomplete and optionally summed up tonic-clonic seizures, just as idiopathic (essential) summed up epilepsy. Both straightforward and complex incomplete seizures and optionally summed up tonic-clonic seizures are diminished by lamotrigine [1] The system of activity of the medication in patients with bipolar turmoil might be identified with the hindrance of sodium and calcium diverts in presynaptic neurons and ensuing adjustment of the neuronal film. [2] Mechanism of activity of LTG is the stamped restraint of arrival of the excitatory synapse's glutamate and aspartate under states of supported dreary terminating. LTG seems to do this by obstructing voltage-sensitive sodium channels and has no immediate impact on JV-methyl-D-aspartate (NMDA) receptors.[3]

Lamotrigine was by and large very much endured in upkeep concentrates with the most well-known unfavorable occasions being migraine, sickness, disease and a sleeping disorder. [5-6] Incidences of loose bowels and quake were essentially lower in lamotrigine-than in lithium-treated patients. The incidence of genuine rash with lamotrigine treatment was $0.1 \%$ in all investigations of bipolar problem and included one instance of gentle Stevens-Johnson condition. Lamotrigine didn't

Address for Correspondence: Samina Alam, Faculty of Pharmacy, Jinnah University for Women, Karachi, Pakistan; E-mail: saminaalam03@gmail.com

How to Cite this Article: Samina Alam, Ayesha Qadir, Tanveer Alam, Aqsa Abdul Aziz, Faiza Jabbar, Hareema Hashmi, Khushbu Sabahat, Minal Zahid, Mishra Binte Naeem. In-vitro Dissolution Study of Lamotrigine Tablet in the Presence of Different Medium.World J Pharm Sci 2021; 9(9): 187-191.

This is an open access article distributed under the terms of the Creative Commons Attribution-NonCommercialShareAlike 4.0 International License, which allows adapt, share and build upon the work non-commercially, as long as the author is credited and the new creations are licensed under the identical terms. $(\mathrm{cc})$ EY-NC-SA 
seem to cause bodyweight gain.[4] Oral lamotrigine is promptly bioavailable (98\%), and goes through insignificant first-pass digestion. incorporation of lamotrigine is unaffected by food. Direct pharmacokinetics show top lamotrigine focuses happening 1-3 hours after a portion. Mean protein restricting is 55-68\% and the medication is generally circulated to all organs and tissues, including mind tissue. It additionally crosses the placenta and is found in the embryo and in bosom milk. Lamotrigine is broadly utilized in the liver, devastatingly through $\mathrm{N}$-glucuronidation (the raterestricting advance in end of the medication). Freedom is $1.6-2.6 \mathrm{~L} / \mathrm{h}$ and the mean plasma disposal half-life is 25-35 hours. [7-8] Normal measurements of lamotrigine range from 50 to 400 $\mathrm{mg}$ /day relying upon a compound prompting or hindering comedication. [9-10] Therapeutic plasma groupings of the medication are not known; however, a putative remedial scope of 1 to $4 \mathrm{mg} / \mathrm{L}$ has been proposed. A few patients have endured fixations $>10 \mathrm{mg} / \mathrm{L}$ with advantage and without clinical poisonousness. The benefit of estimating the convergences of lamotrigine in assisting with enhancing the measurements or decrease the probability of unfriendly impacts has not been established.[11] Safety information from a few enormous examinations demonstrate that the rate of antagonistic impacts of the medication is low and that undesirable impacts are reversible.[5,12]

\section{MATERIALS AND METHODS}

Reference standard of lamotrigine provided by Jinnah university for women Karachi.

Instruments; A Double beam Shimadzu UVvisible spectrophotometer (UV mini-1700, Shimadzu Corporation, Kyoto, Japan with $1 \mathrm{~cm}$ quartz cells). HANNA HI $2211 \quad \mathrm{pH}$ meter(Romania),automated six-basket tablet dissolution tester Galvano scientific Standard electrical balance for weighing.

Collection of samples; Lamictal and lament 50mg available market brand (manufacturing date not exceed more than four months ago from the purchasing time) was collected. the sample was properly checked

Preparation of standard solution: A tablet is dissolved in $100 \mathrm{ml}$ water.

\section{Preparation of dissolution medium:}

1-Preparation of green tea: Bring $20 \mathrm{ml}$ of water to boil now put 2 tea bags in a beaker and poured $880 \mathrm{ml}$ of distilled water. allow infusion for 2-3 min and then dip the tea bags in a beaker 8-10 times. After preparation of green tea solution mix well before placed in dissolution basket with $900 \mathrm{ml}$ of green tea solution. Take tablet and placed in the vessel and the apparatus was assembled. the operation in the green tea medium was carried for 60minutes.After every 15 minutes sample solution was withdrawn till 60 minutes and filtered. The released drug was assayed by using UV spectrophotometer at $302 \mathrm{~nm}$.

\section{Dissolution method for lamotrigine:}

Medium distilled water

Apparatus: Paddel, dissolution with 100 rpm

Time 60 minutes

Procedure: Take $900 \mathrm{ml}$ of distill water in a beaker then placed in disintegration apparatus, and poured 1 tablet in a vessel and assembled it. The operation in this medium was also carried for 60 minutes. after every 15 minutes withdraw the sample and filtered. The released drug was assayed by using spectrophotometer at $302 \mathrm{~nm}$. Follow the same procedure for both brand and observed the absorbance.

\section{RESULTS}

Dissolution testing is an in vitro method vital in plan and improvement of drug dose structures, as it tends to be utilized as a substitute for in vivo concentrates under rigorously characterized and indicated conditions. The objective of the current examination is to direct the relative dissolution investigations of different brands of same measurements structures and treatment of acquired dissolution information table 1 indicates the product detail of the brands used in this this research study. Table 2 indicates the specifications and parameters used to performed this dissolution study and table 3, 4 and 5 revealed the absorbances of the brands in respective mediums i.e distilled water and tea extracts. Figure 1, 2, 3 and 4 showed the results of absorbances differences in graphical formats.

Table 01: Product information

\begin{tabular}{|l|l|l|}
\hline S no. & & PRODUCT DETAIL \\
\hline 1 & Company name & GSK, Glitz, Searle \\
\hline 2 & Generic name & lamictal \\
\hline 3 & Mfg Date & $08-2018$ \\
\hline 4 & Exp.date & $08-2020$ \\
\hline 6 & Apperance & $\begin{array}{l}\text { Square shape, off white } \\
\text { color }\end{array}$ \\
\hline
\end{tabular}

TABLE 02: Parameters and specifications

\begin{tabular}{|l|l|}
\hline PARAMETER & SPECIFICATION \\
\hline Dissolution medium & Green tea, water \\
\hline volume & $900 \mathrm{ml}$ \\
\hline Wavelength measurement & 302 \\
\hline Rotation per minutes & 100 \\
\hline Time & $60 \mathrm{~min}$ \\
\hline
\end{tabular}


Table 03: Dissolution of brand 1(lamictal) in distilled water:

\begin{tabular}{|l|l|l|l|l|}
\hline TIME & $15 \mathrm{~min}$ & $30 \mathrm{~min}$ & $45 \mathrm{~min}$ & $60 \mathrm{~min}$ \\
\hline ABSORBANCE & 0.385 & 0.371 & 0.394 & 0.440 \\
\hline
\end{tabular}

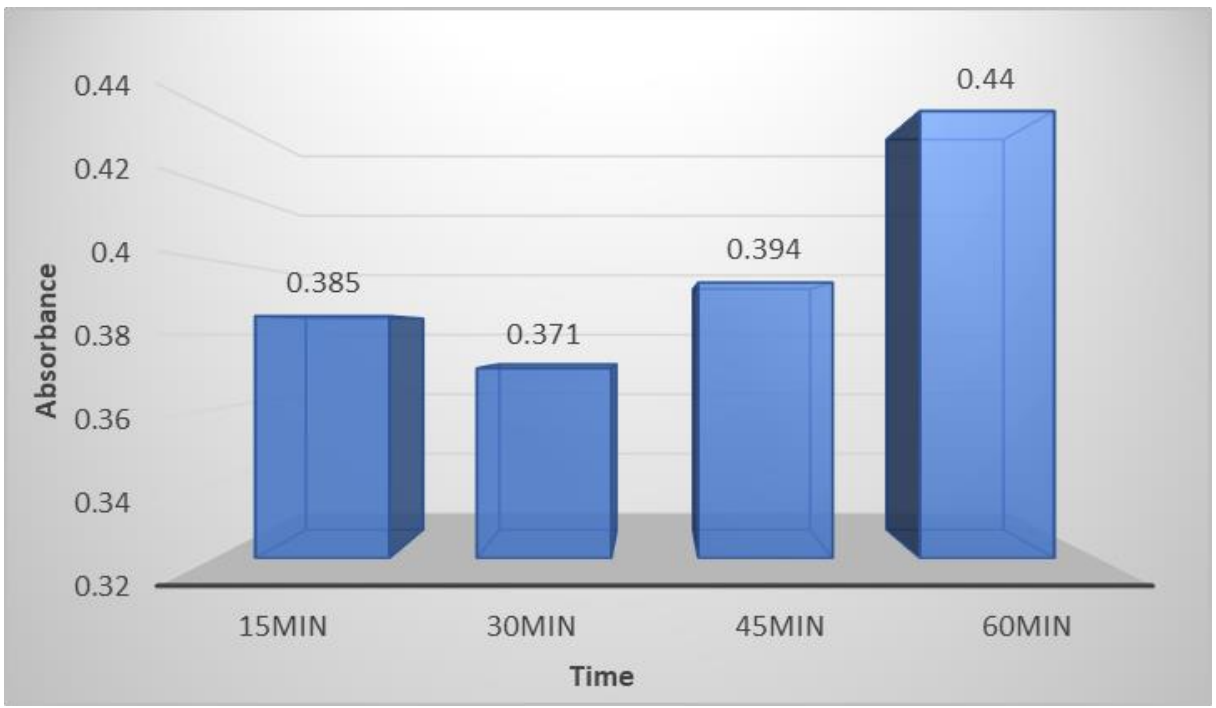

Figure 1: Dissolution of lamictal in distilled water

Table 04: Dissolution of Brand 1 In Distilled Water+Tea Extract:

\begin{tabular}{|l|l|l|l|l|}
\hline TIME & $15 \mathrm{~min}$ & $30 \mathrm{~min}$ & $45 \mathrm{~min}$ & $60 \mathrm{~min}$ \\
\hline ABSORBANCE & 0.579 & 0.385 & 0.364 & 0.344 \\
\hline
\end{tabular}

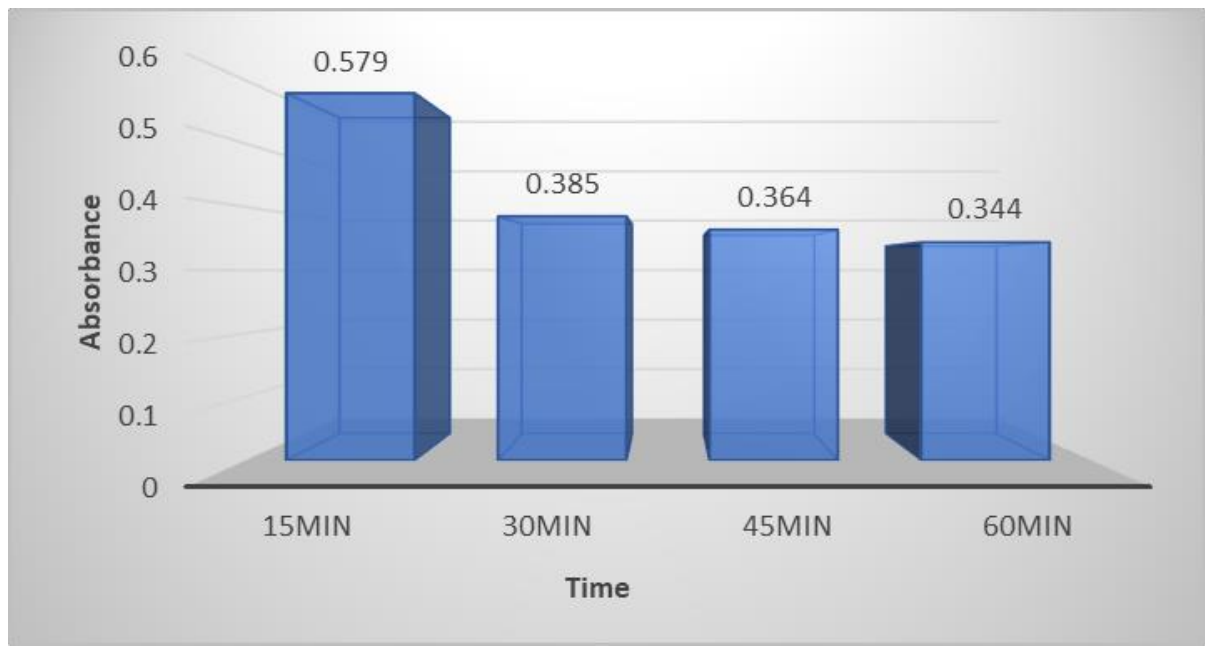

Figure 2: Dissolution Of Brand 1 In Distilled Water+Tea Extract

Table 05 Dissolution Of Brand 2(Lamnet) In Distilled Water:

\begin{tabular}{|l|l|l|l|l|}
\hline$:$ TIME & $15 \mathrm{~min}$ & $30 \mathrm{~min}$ & $45 \mathrm{~min}$ & $60 \mathrm{~min}$ \\
\hline ABSORBANCE & 1.371 & 1.64 & 1.67 & 1.71 \\
\hline
\end{tabular}




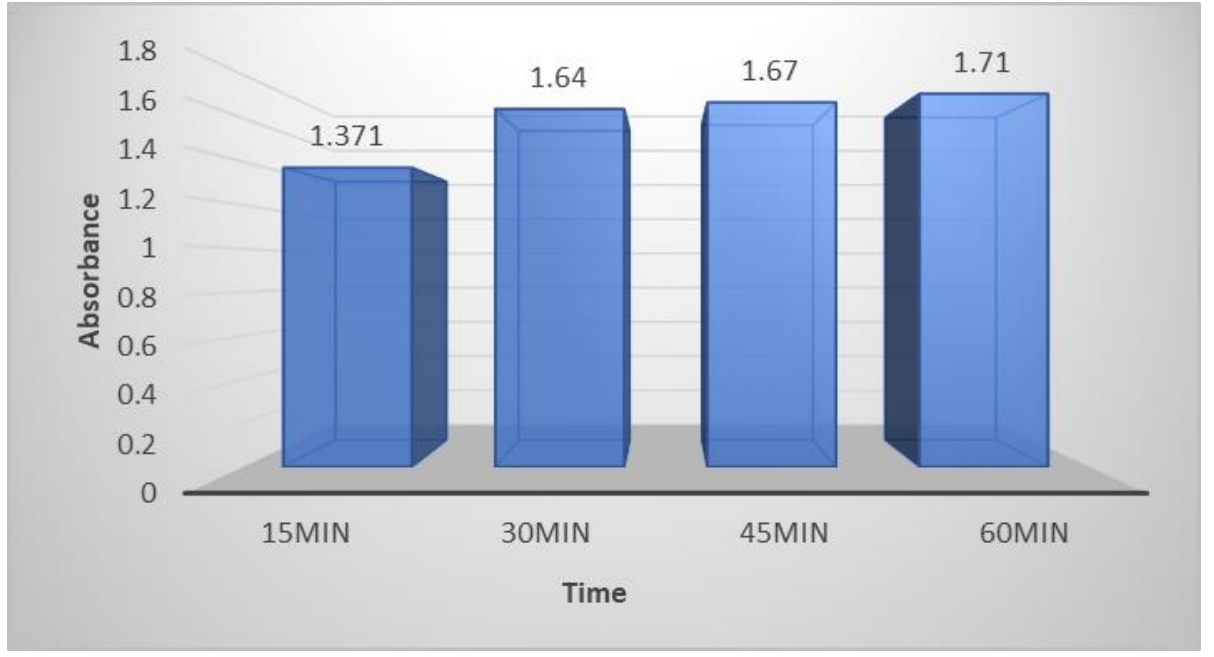

Figure 3: Dissolution Of Brand 2(Lamnet) In Distilled Water

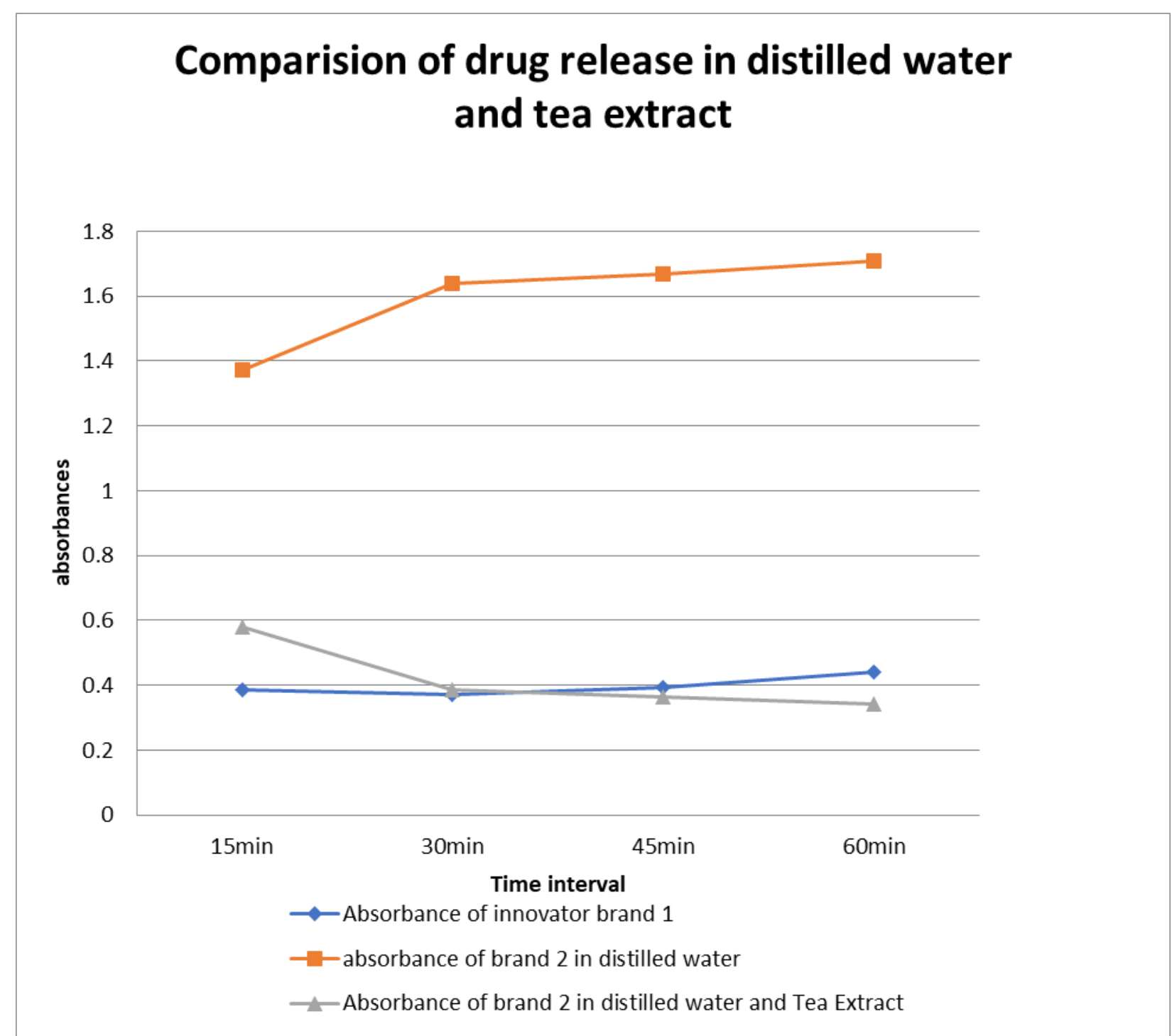

Figure 4: Comparison of dissolution in different mediums 


\section{DISCUSSION}

We have performed the dissolution rate of lamotrigine by taking different brands i.e lamictal and lamnet in different medium. The mediums we used were distilled water and tea extract .We used dissolution assembly and taken reading at different time by taking absorbance. The brand1 lamictal dissolution in distilled water increases with time. Brand 2 lamnet, showed more dissolution than lamictal i.e its absorbance at $60 \mathrm{~min}$ were 1.71 , and then we changed the medium that is tea extract, In tea extract we dissolved brand 2 and its absorbance decreases with time.

CONCLUSION; Evaluation of the dissolution study of tablets showed that all brands fulfilled the requirements of the USP. but by observation we conclude that lamotrigine shows interaction with tea extract i.e its absorbance decreases with time it should not take with tea.

\section{REFERENCES}

1. Fitton, A. and Goa, K.L., 1995. Lamotrigine. Drugs, 50(4), pp.691-713.

2. Goldsmith, D.R., Wagstaff, A.J., Ibbotson, T. and Perry, C.M., 2003. Lamotrigine. Drugs, 63(19), pp.2029-2050.

3. Messenheimer, J.A., 1995. Lamotrigine. Epilepsia, 36, pp.S87-S94.

4. Goldsmith, D. R., Wagstaff, A. J., Ibbotson, T., \& Perry, C. M. (2003). Lamotrigine. Drugs, 63(19), 2029-2050.

5. Rambeck, B. and Wolf, P., 1993. Lamotrigine clinical pharmacokinetics. Clinical pharmacokinetics, 25(6), pp.433-443.

6. Leach MJ, Marden CM, Miller AA. Pharmacological studies on lamotrigine, a novel potential antiepileptic drug: II. Neurochemical studies on the mechanism of action. Epilepsia. 1986 Oct;27(5):490-7.

7. Burstein AH. Lamotrigine. Pharmacotherapy: The Journal of Human Pharmacology and Drug Therapy. 1995 Mar 4;15(2):129-43.

8. Garnett WR. Lamotrigine: pharmacokinetics. Journal of child neurology. 1997 Nov;12(1_suppl):S10-5.

9. Rambeck B, Wolf P. Lamotrigine clinical pharmacokinetics. Clinical pharmacokinetics. 1993 Dec;25(6):433-43.

10. Vaithianathan S, Raman S, Jiang W, Ting TY, Kane MA, Polli JE. Biopharmaceutic risk assessment of brand and generic lamotrigine tablets. Molecular pharmaceutics. 2015 Jul 6;12(7):2436-43.

11. Patil C, Das S. Effect of various superdisintegrants on the drug release profile and disintegration time of Lamotrigine orally disintegrating tablets. African journal of pharmacy and pharmacology. 2009 Jan 31;5(1):76-82.

12. Ruiz A, Cuesta F, Parra S, Montoya B, Restrepo M, Archbold R, Pena L, Holguin G. Bioequivalence Evaluation of Two Formulations of Lamotrigine Tablets in Healthy Volunteers. J Bioequiv Availab. 2012;4(3):030-4. 